\title{
Process dimensions and effectiveness of information systems planning: An empirical study on the implementation status of Chinese enterprises
}

(C) Higher Education Press and Springer-Verlag 2007

\begin{abstract}
Information systems planning (ISP) is a critical concern for top executives and chief information officers (CIOs) of enterprises. This paper summarizes the process dimensions of ISP and proposes a descriptive model to describe these dimensions and their relationships with the planning effectiveness. The research model is empirically tested by the data collected from 125 Chinese big companies. Our results indicate: (1) the way of initiating and implementing the information system (direction of planning flow) significantly influences the other dimensions of ISP; (2) ISP is a non-technology-driven managerial activity. Thus dimensions on the organizational level, rather than technology-related process dimensions, strongly influence ISP effectiveness.
\end{abstract}

Keywords information systems planning, process model, planning process, planning effectiveness

摘要 随着信息技术在企业中的普及应用, 信息系统规划成为企业信息经理 和高层管理者最关注的课题之一。通过对信息系统规划的过程特征进行梳理 和分类, 建立反映过程特征以及过程特征与规划有效性之间关系的描述模型。同 时, 收集 125 家中国企业的数据，并应用这些数据对模型进行实证检验，发 现：（1）规划的发起方式对规划过程的其他特征有显著的影响; (2) 信息系统规划

Received July 10, 2007

LI Dong $(\bowtie)$, CAI Jian

Guanghua School of Management, Peking University, Beijing 100871, China

E-mail: lidong@gsm.pku.edu.cn

NIU Fang

School of Business, Nankai University, Tianjin 300071, China 
是一个非技术主导的组织管理活动, 技术层面的过程特征对规划有效性的影响不 显著, 而组织层面的过程特征对规划有效性有显著的影响。

关键词 信息系统规划, 过程模型, 规划过程, 规划有效性

\section{Introduction}

Information systems planning (ISP) is a process of defining objectives for organizational computing and identifying suitable potential information technology (IT) applicable to the company. The increasing impact of information systems (IS) on business performance has made ISP a key management issue for practitioners and academics alike (Moynihan, 1990; Niderman et al., 1991).

In China, since IT began to be applied either to support business strategies or to create strategic opportunities, investment in information systems has increased rapidly. Some Chinese companies, such as Bangwei, Lifung, have gained great success by applying IT. But for most Chinese companies, it is still a challenge to align IT with their business strategies. Information systems planning has gained much attention in recent years. A survey in 2005 reported that ISP was one of the key management issues for chief information officers (CIOs) of China (Yang, 2003, Li and Huang, 2005).

Within information systems research, significant effort has been devoted to improving the planning effectiveness. Early studies focused on developing frameworks and methodologies for ISP. Some methodologies, such as Business System Planning (BSP), information engineering, and critical success factors (CSFs), are well known to scholars and practitioners alike. Although existing frameworks and methodologies provide some direction for information systems planning, many important dimensions of ISP remain unaddressed (Segars et al., 1998). For example, it is not clear how a methodology is (or should be) actually implemented and how the process of planning is initiated.

To provide a comprehensive view of ISP, some studies were conducted to identify the process dimensions. Das et al. (1991) and Lederer and Sethi (1996) developed process dimensions (prescriptions) to describe the planning process. Earl (1993), Pyburn (1983) and Sabherwal and King (1995) identified the differences among various companies' IS planning processes or IS decisionmaking through field studies. Segars et al. (1998) developed process dimensions and empirically tested their impact on planning effectiveness.

Although these studies of dimensions provided some descriptions of the planning process, they have not been implemented in China and the relationships among the process dimensions remain unclear. Information systems planning is a system which is structured by the process dimensions. So there may be certain relationships among different process dimensions. Understanding these 
relationships can help practitioners and academics view the ISP more systemically, especially for current Chinese enterprises.

The purpose of this study is to propose a process model to describe the current Chinese enterprises' structure of ISP, which exhibits not only the relationship between process dimensions and the effectiveness of the planning process, but also the relationships among different dimensions of the planning process. The remainder of the paper is organized as follows. Section 2 discusses and provides process dimensions of ISP. Section 3 presents the process model and proposes related hypotheses, followed by outlining analytical techniques and item measurements. Empirical test results, study implications and limitations are discussed in the last section.

\section{Process dimensions and planning effectiveness}

To study the relationship between process dimensions and planning effectiveness, we need to first of all identify the process dimensions and the definition of planning effectiveness. Some researchers took ISP as a planning system and identified the potential dimensions of ISP through field studies (Pyburn, 1983; Sullivan, 1985; Earl, 1993 and Sabherwal and King, 1995). Earl (1993) identified five kinds of ISP approaches according to the differences in applied methods, participants and the initiation of ISP. In the business-led approach, users and line managers are very little involved and the emphasis is on the business-led IS. The administrative approach establishes formal procedures for allocating IS resources. Since the IS proposals are submitted by business units or departments, the initiation of ISP can be seemed as a bottom-up process. The technological approach and method-driven approach emphasize the importance of methods or technologies. Both of them make highly formal procedure in ISP. In the organizational approach, the emphasis is on management understanding and involvement. The methods are applied as required or to fit particular purposes. Through the above brief review of the studies on ISP characteristics (e.g. Das et al. 1991, Lederer and Sethi, 1996; Segars et al. 1998;) we can summarize the five important dimensions of the planning process as below (as shown in Table 1).

\section{Research model and hypotheses}

Along the planning process, there are normally three stages: initiation stage, analysis stage and output stage. At the initiation stage, the members of an organization provide proposals for planning. Planning flows may be top-down 
Table 1 Dimensions of IT planning process

\begin{tabular}{|c|c|}
\hline Comprehensiveness & $\begin{array}{l}\text { Comprehensiveness refers to "the extent to which an organization } \\
\text { attempts to be exhaustive or inclusive in making and integrating } \\
\text { strategic decisions" (Fredrickson, 1984). High level } \\
\text { comprehensiveness means intensively collecting information, } \\
\text { surveying a full range of objectives and evaluating a range of } \\
\text { alternatives. }\end{array}$ \\
\hline Formalization & $\begin{array}{l}\text { Formalization refers to the extent to which the planning process is } \\
\text { structured (Das et al. 1991). A highly formalized planning system } \\
\text { is characterized by written policies and procedures or formalized } \\
\text { methodologies applied in the planning process. }\end{array}$ \\
\hline Control & $\begin{array}{l}\text { Control is the control of the planning process and IT resources (Hann } \\
\text { and Weber, 1996; Segars et al., 1998). In a planning process which } \\
\text { focuses on control, the top management monitors the process, the } \\
\text { collected information is checked thoroughly and cost/benefit } \\
\text { analysis is carried out. }\end{array}$ \\
\hline Planning flow & $\begin{array}{l}\text { The planning flow refers to the assignation of authority and/or } \\
\text { devolution of responsibility for strategic planning (Segars et al., } \\
\text { 1998). There are two types of planning flows: top-down planning } \\
\text { flow and bottom-up planning flow. A top-down planning flow means } \\
\text { that the top management initiates ISP while functional management } \\
\text { is involved in the initiation of ISP in a limited way. Conversely, } \\
\text { a bottom-up planning flow means functional management takes } \\
\text { greater initiative for ISP while the top management only oversees } \\
\text { the proposals formulated and submitted by the lower rungs of the } \\
\text { management. }\end{array}$ \\
\hline Participation & $\begin{array}{l}\text { Participation refers to involvement of different rungs and departments } \\
\text { of the organization in the planning process. The planners may come } \\
\text { from various organizational units and levels of participation may } \\
\text { vary. Broad participation means high involvement of members of } \\
\text { different organizational units. }\end{array}$ \\
\hline
\end{tabular}

or bottom-up, depending upon organizational characteristics. At the analysis stage, the planners analyze the organization and the environment to identify the information systems which are most suitable for meeting organizational needs. The dimensions of comprehensiveness, control, participation and formalization describe this stage. In the end, that is, at the output stage, the plan is formulated. The plan may specify explicitly the potential information system that should be implemented, the order of the priority of the information system and resources needed for implementation. Effectiveness is measured by evaluating the contribution of the plan. The three stages that form our research model are shown in Fig. 1.

When the potential information system is identified, the organizational structural characteristics will affect ISP. Major organizational structural 


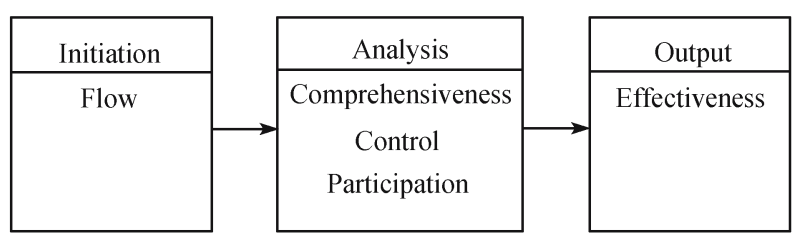

Fig. 1 Research model

characteristics include methodologies for ISP, members of organizational subunits, and the extent of control of the top management over the planning process and so on. A top-down planning flow means the top management assumes the responsibility for initiating the planning process and they have greater say and authority than functional management. So planning initiated by the top management absorbs more attention and resources than that initiated by functional management. Thus we propose the following hypothesis.

Hypothesis 1. Information systems planning with a top-down flow has a higher level of comprehensiveness, formalization, control and participation than ISP with a bottom-up flow.

Information systems planning is a complex process which needs collection and analysis of vast amounts of information about organizational business, markets, policy and environment, etc. Formal and comprehensive analysis could improve the quality of decision-making and the effectiveness of ISP (Das et al. 1991; Rowley, 1994; Segars et al. 1998; Brown, 2004). We, therefore, assume that

Hypothesis 2. The higher the level of comprehensiveness and formalization is, the more effective ISP becomes.

In ISP, information is collected from different functional and operational areas for individuals from different areas who know their own information needs. Involvement of organizational subunits in ISP also serves as a communication channel to express their information needs. A broad participant profile may also be necessary to offset the planning team's limited knowledge about the business and dynamics of the environment. Teo and Ang (1999) pointed out that the communication between IS departments and user departments is a critical factor for successful alignment of ISP with business planning. We thus propose that

Hypothesis 3. The higher the level of participation is, the more effective ISP becomes.

Resource constraints and incomplete implementation are features of unsuccessful ISPs (Earl, 1993). Control on the process and IT resources can ensure that the cost of an IS is within organizational budgets. Also, the top management's objectives can be reflected in the planning process and that increases the usefulness of the IS plan (Hann and Weber, 1996).

Hypothesis 4. The higher the level of control, the more effective ISP becomes. 


\section{Research design}

To reduce the confounding effects of other factors, we selected the fulfillment of ISP's objectives as the criteria to measure planning effectiveness. Objectives include aligning IS with business needs, seeking competitive advantages from IT, forecasting IS resource requirements, etc. (Earl, 1993). The complete set of measures for the five dimensions of ISP and planning effectiveness is shown in Table 2.

Table 2 Item measures of process dimensions and effectiveness

\begin{tabular}{|c|c|c|}
\hline Dimensions & Variable & Description \\
\hline \multirow[t]{4}{*}{ Flow } & $\mathrm{X} 1$ & ISP is initiated at the highest levels of the organization. \\
\hline & $\mathrm{X} 2$ & Top management drives ISP. \\
\hline & $\mathrm{X} 3$ & Top management endorses ISP. \\
\hline & $\mathrm{X} 4$ & $\begin{array}{l}\text { Those who initiate ISP are not responsible for formulating } \\
\text { the IS plan. }\end{array}$ \\
\hline \multirow[t]{3}{*}{ Comprehensiveness } & $\mathrm{X} 5$ & We collect a great deal of information. \\
\hline & $\mathrm{X} 6$ & $\begin{array}{l}\text { We analyze the organization and environment } \\
\text { comprehensively. }\end{array}$ \\
\hline & $\mathrm{X} 7$ & We designed several alternates for the IS plan. \\
\hline \multirow[t]{3}{*}{ Formalization } & $\mathrm{X} 8$ & $\begin{array}{l}\text { We utilize formalized planning techniques in the ISP } \\
\text { process. }\end{array}$ \\
\hline & X9 & Our ISP process is very structured. \\
\hline & $\mathrm{X} 10$ & We make a schedule for the ISP process. \\
\hline \multirow[t]{4}{*}{ Participation } & $\mathrm{X} 11$ & $\begin{array}{l}\text { There are representatives from functional areas participating } \\
\text { in ISP. }\end{array}$ \\
\hline & $\mathrm{X} 12$ & $\begin{array}{l}\text { Staff from technology and management departments } \\
\text { participates in ISP. }\end{array}$ \\
\hline & $\mathrm{X} 13$ & $\begin{array}{l}\text { The planners often communicate with staff of business } \\
\text { units. }\end{array}$ \\
\hline & $\mathrm{X} 14$ & Top management gives support and instructions for ISP. \\
\hline \multirow[t]{5}{*}{ Control } & $\mathrm{X} 15$ & $\begin{array}{l}\text { ISP is viewed as a means of controlling the growth of } \\
\text { technology. }\end{array}$ \\
\hline & $\mathrm{X} 16$ & ISP focuses on control of IT investment through budgeting. \\
\hline & $\mathrm{X} 17$ & We conduct benefit/cost analysis in ISP. \\
\hline & $\mathrm{X} 18$ & $\begin{array}{l}\text { We often check collected information and output of } \\
\text { analyses. }\end{array}$ \\
\hline & X19 & We often report progress of ISP to superiors. \\
\hline \multirow[t]{6}{*}{ Effectiveness } & Y1 & The IS identified in ISP supports the business strategy well. \\
\hline & $\mathrm{Y} 2$ & The IS identified in ISP meets organizational needs. \\
\hline & Y3 & ISP benefits the allocation of resources to key IT projects. \\
\hline & Y4 & ISP enables us to integrate the IS in our firms. \\
\hline & Y5 & $\begin{array}{l}\text { We are able to identify new IT-based opportunities before } \\
\text { our competition. }\end{array}$ \\
\hline & Y6 & ISP enables us to make better IT investment decisions. \\
\hline
\end{tabular}




\section{Data collection}

We selected CIOs and IT office leaders as respondents to obtain accurate information about ISP. The sample frame adopted is the list of CIOs and IT leaders on the website www.cioleader.com. This website provides the names, addresses and titles of some CIOs and IT office leaders in China. From the list, 400 firms were randomly chosen as target population.

From April to June in 2006, 136 questionnaires were returned (response rate $=34 \%$ ). Of the returned responses, 11 provided inadequate information and were not suitable for analysis. The majority of respondents (33.4\%) were from the manufacturing industry. Each category of the remaining sample represented less than $15 \%$ of the total sample. Most of these respondents $(90.6 \%)$ work in companies having annual sales revenue more than one billion RMB yuan, and $47.2 \%$ of the sampled companies had annual sales revenue more than 50 billion RMB yuan.

\section{Results}

\subsection{Validity and reliability}

The validity and reliability of the multi-item indicators used for measuring various constructs should be tested. Validity is normally evaluated using three forms of validity, namely content, convergent and discriminant validity.

Content validity is established through the process used in identifying and refining items through various pre-testing procedures. In our study, we referred to related scales and pretested the scales on 37 IS executives, functional managers and top managers to ensure content validity.

Unidimensionality, which assesses the existence of a single trait or construct underlying a set of measures, has been used as a measure of convergent validity. We used exploratory factor analysis to examine whether there is only one construct in the measures of each process dimension and planning effectiveness. After removing items X4, X15, X16 and Y5 because of low loading, there was only one eigenvalue greater than 1 for each of the process dimensions, and planning effectiveness. The loadings of remaining items were all greater than 0.6. Thus we could claim that the measurement scales of each process dimension and planning effectiveness make one single construct.

Discriminant validity can be tested by the structural equation modeling technique by comparing an unconstrained model with the constrained model, where the correlation between the constructs is constrained to unity (Premkumar and King, 1994). Table 3 shows all the results of pairwise tests. $\chi^{2}$ difference 
values in the table are significant at $P<0.001$, indicating that all variables exhibit significant discriminant validity.

Table 3 Assessment of discriminant validity

\begin{tabular}{lcccc}
\hline Variables & $\begin{array}{c}\text { Unconst. Model } \\
\text { Chi-Square (df) }\end{array}$ & $\begin{array}{c}\text { Const. Model } \\
\text { Chi-Square (df) }\end{array}$ & $\begin{array}{c}\text { Chi-Square } \\
\text { Difference }\end{array}$ & Sig. \\
\hline Comprehensiveness-Formalization & $14.59(8)$ & $31.46(9)$ & 16.87 & 0.001 \\
Comprehensiveness-Participation & $20.37(13)$ & $91.02(14)$ & 70.05 & 0.001 \\
Comprehensiveness-Control & $6.30(8)$ & $55.37(9)$ & 49.07 & 0.001 \\
Comprehensiveness-Planning flow & $11.34(8)$ & $103.22(9)$ & 91.88 & 0.001 \\
Formalization-Participation & $32.82(13)$ & $78.61(14)$ & 45.79 & 0.001 \\
Formalization-Control & $11.89(8)$ & $50.18(9)$ & 38.29 & 0.001 \\
Formalization-Planning flow & $8.47(8)$ & $66.31(9)$ & 57.84 & 0.001 \\
Participation-Control & $25.68(13)$ & $48.50(14)$ & 22.82 & 0.001 \\
Participation-Planning flow & $30.13(13)$ & $113.92(14)$ & 83.79 & 0.001 \\
Control-Planning flow & $19.48(8)$ & $65.32(9)$ & 45.84 & 0.001 \\
\hline
\end{tabular}

The most frequently used measure for reliability assessment is Cronbach's $\alpha$ (Nunally, 1978). The reliability values of comprehensiveness, formalization, control, planning flow, participation and planning effectiveness are $0.68,0.65$, $0.84,0.71,0.83$ and 0.76 respectively, all indicating that the construct exhibits acceptable reliability.

\subsection{Structural equation modeling}

As hypothesized, the planning flow has a direct influence on comprehensiveness, formalization, control and participation while comprehensiveness, formalization, control and participation have a direct influence on planning effectiveness. Fig. 2 illustrates the results of the structural equation model. The observed $\chi^{2}$ for the model is 364.17. Adjusting this value for degrees of freedom results in a normed $\chi^{2}$ of 1.99 , which is well below the suggested cutoff 5.0. The normed $\chi^{2}$ indicates a good overall fit.

As shown in Fig 2, the paths from flow to comprehensiveness, participation, control and formalization are all moderately strong and positive. This implies that the ISP with a top-down flow has higher levels of comprehensiveness, formalization, control and participation than that with a bottom-up flow. Thus Hypothesis 1 is supported.

The paths from control and participation to planning effectiveness are also positively significant at 0.05 . This supports both Hypotheses 3 and 4, the higher the level of control and participation, the more effective ISP becomes. 


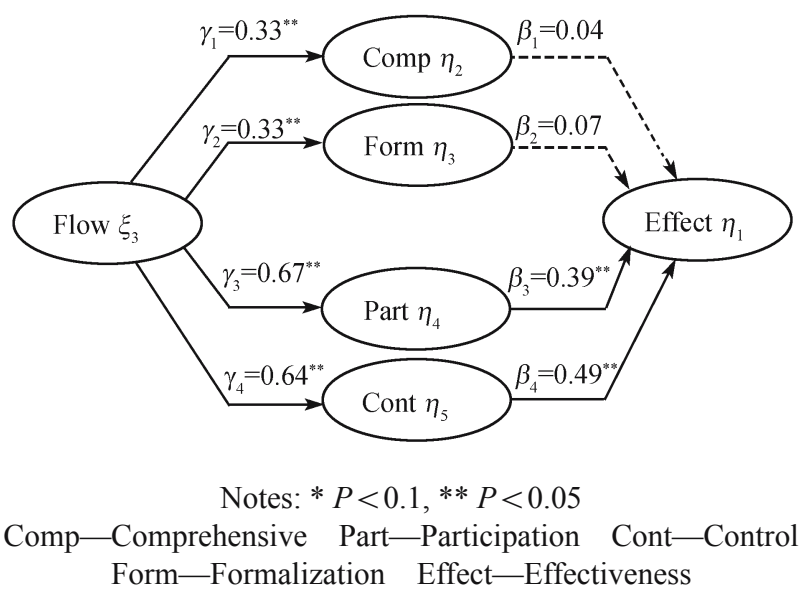

Fig. 2 Structural equation model

However, the path from formalization and comprehensiveness to planning effectiveness is weak. This result indicates that formalization and comprehensiveness have no direct influence on planning effectiveness, which is not consistent with Hypothesis 2. This seems to suggest that the amount of collected information (comprehensiveness) and formal methodologies (formalization) are not key factors affecting planning effectiveness. Perhaps this is because applying formal methodologies and collecting information can not make the collected information reflect organizational information needs sufficiently. To make the collected information accurately reflect organizational information needs, ISP should involve participants from business units to express their own information needs and the process should be controlled to ensure that the collected information is correct.

\section{Conclusions and limitations}

This study develops a model to describe the structure of the ISP system. The results of our empirical study indicate two major findings. First, the planning flow has a direct influence on process dimensions, participation, control, formalization and comprehensiveness. Second, participation and control influence planning effectiveness while formalization and comprehensiveness do not.

The findings from this study have identified many new topics for future research. For instance, the development of the process model provides an opportunity to study the reasons why planning effectiveness varies in different industries. This study also provides a framework for future detailed studies about ISP, such as studies of factors critical for successful solutions of ISP problems. 
Also, the findings of this study have practical implications for practitioners that can help improve planning effectiveness. According to the process model, ISP should be initiated by the top management so that ISP can get enough resources. Meanwhile, the relationships between process dimensions and planning effectiveness imply that during analysis, ISP should involve participants from different areas and the process should be controlled or monitored to ensure that the collected information is correct.

Although this study tries to formulate a structure of the planning process, it still contains some inherent limitations. The first limitation is that most of the samples have come from large companies of China. Whether the results of the empirical study can be expanded to small companies or companies in other countries needs further testing. The second limitation is that perhaps some other process dimensions have been ignored. Because ISP is a complex process, it is hardly possible to exhaust all process dimensions in one study.

\section{References}

Ang J S K, Quek S A, Teo T S H, Lui B (1999). Modeling IS planning benefits using ACE. Decision Sciences, 30(2): 533-562

Brown I T J (2004). Testing and extending theory in strategic information systems planning through literature analysis. Information Resource Management Journal, 17(4): 20-48

Das S R, Zahra S A, Warkentin M E (1991). Integrating the content and process of strategic MIS planning with competitive strategy. Decision Sciences, 22(5): 953-983

Earl M J (1993). Experiences in strategic information systems planning. MIS Quarterly, 17(1): $1-23$

Fredrickson J W (1984). The comprehensiveness of strategic decision process: Extension, observations, and future directions. Academy of Management Journal, 27(3): 445-466

Hann J, and Weber R (1996). Information systems planning: A model and empirical tests. Management Science, 42(7): 1043-1064

Lederer A L, Sethi V (1996). Key prescriptions for strategic information systems planning. Journal of Management Information Systems, 13(1): 35-62

Li D, Huang W (2005). Key issues in information systems management: China's perspective. The Ninth Pacific-Asia Conference on Information Systems, Bangkok, Thailand

Moynihan T (1990). What chief executives and senior managers want from their IS Departments. MIS Quarterly, 14(1): 15-26

Niderman F, Brancheau J C, Wetherbe J C (1991). Information systems management issues for the 1990s. MIS Quarterly, 15(4): 475-500

Nunnally J, ed (1978). Psychometric Theory. NY: McGraw-Hill

Porter M E, Millar V E (1985). How information gives you a competitive advantage. Harvard Business Review, 63(3): 149-160

Premkmar G, King W R (1994). Organization characteristics and information systems planning: An empirical study. Information Systems Research, 5(2): 75-109

Pyburn P J (1983). Linking the MIS with corporate strategy: An exploratory study. MIS Quarterly, 7(2): 1-14 
Rowley J (1994). Strategic information systems planning: Designing effective systems. Business Executive, 8(50): 154-155

Sabherwal R, King W R (1995). An empirical taxonomy of the decision-making processes concerning strategic application of information systems. Journal of Management Information Systems, 11(1): 177-214

Segars A H, Grover V, Teng J T C (1998). Strategic information systems planning: Planning systems dimensions, internal Co alignment, and implements for planning effectiveness. Decision Sciences, 29(2): 303-345

Sullivan C H (1985). Systems planning in the information age. Sloan Management Review, 26(2): 3-12

Teo T S H, Ang J S K (1999). Critical success factors in the alignment of IS plans with business plans. International Journal of Information Management, 19: 173-185

Yang Q (2003). Business Planning and Information Systems Planning. Beijing: Economy and Management Publishing House 